\title{
Provision of trauma care in Ministry of Public Health Hospitals Regional Health 3 Thailand
}

\author{
Nathakrid Thammakawinwong \\ Faculty of Community Health, Lampang Rajabhat University, Thailand \\ Nathakrit2014@gmail. com
}

\begin{abstract}
Road accident tends to rise, resulting in enormous loss of lives and assets. According to statistics of deaths from road accident from The World Health Organization found that Thailand mortality rate was 38.1 deaths per 100,000 populations and 3rd in the world ranking. The purpose of this report was to study the situation of trauma care process in Ministry of Public Health hospitals in regional health 3 through mixed methodology research. 390 traumatic patients were randomized from Emergency Department and 59 of administrators and staffs were interviewed and group discussed. The result found that most traumatic patients were urgent. The average time of care in Emergency Department was 86.4 minutes. Most were highly satisfied to the services. Most traumatic patients entered to hospital privately. Patients who came with ambulance would communicate directly through emergency call of 1669 in trust of the safety system. The problems of Emergency Room management were insufficient of medical personnel especially emergency physicians and inadequate of referral system, budgets, equipment and information system including lacking of coordinated work and integrations with Fast Responder unit of other local government and foundations. The policy recommendations from this study were Ministry of Public Health and Emergency Medical Institute should long-term plan to support emergency physicians and other medical personnel for hospitals in any level in 5-10 years. Including encouragement of local government to participate in developing of emergency system.
\end{abstract}

Keywords - Medical emergency, Trauma care, Ministry of Public Health Hospitals, Accident, Emergency Department.

\section{INTRODUCTION}

Trauma from road accidents and upward trend, resulting in the loss of life and property as invaluable body. Statistics of Thailand deaths from road accidents 13,365 cases, Mortality rate 38.1 per hundred thousand population. Which ranked third in the world [1] Research of Thailand Health Insurance System Research Office of Thailand found that Trauma care system progressed respectively. Was pronounced Total operating resuscitation for trauma. Rising from 82,895 to 155,431 during the years 2010 to 2013 [5] but also many other problems as well. The shortage of medical staff, Referral system during hospital, Information system. Recognizing the barriers that the government has set a strategy for development of emergency medicine for Trauma care and development service quality standards covering population access to the service in hospital [2]

Regional health 3 [3] located in the lower Northern region comprises five provinces including Nakhon Sawan, Uthai Thani, Kamphaeng Phet, Phichit, Chainat and a total population of 3,003,091 persons. People died from road accidents statistics for the years $2011-2013$ found that the mortality rate 38.1 per 100,000 population increase in 2013 (29.1\%) compared to Regional health as a total Regional health3 higher than the national average. And the province with the highest mortality rate in 2013 were Chainat (36.6\%), followed by Nakhon Sawan (32.4\%) Kampangpet $(27.6 \%)$ and Phichit. (23.9\%) [12] This report was to study the situation of trauma care process in Ministry of Public Health Hospitals.

\section{RESEARCH DESIGN AND METHOD}

This research was a mixed methodology which qualitative research and quantitative research Parallel Convergent design [13] divided as follows.

A. Quantitative Research was descriptive study with Cross sectional survey.

1) Participants: The population were 78,541 patients surveyed in Emergency room of hospital in Regional Health 3 and 390 of sample size which calculated. [15] Research tool: The questionnaire was designed as measuring tool of the quality and validated by experts testing. Questions include personal information and trauma patients.

2) Data collection: They were collected by simple random sampling

3) Data analysis: Data were analysis by Descriptive statistic. Questionnaire were designed as measuring tool of the quality of the hospital and validated by experts testing.Data was analysis by Discriminant statistic. 
B. Qualitative Research was phenomenological study

1) Participants: Hospital staffs and rescuers network consists of 59 hospitals, including Chief Medical City, Hospital director, Emergency physicians, Nurses, Staff of emergency department, Finance, Information, Human resource development.

2) Data collection: They were collected by purposive sampling by in-depth interviews and Focus group discussion. [14]

3) Data analysis: Data were analysis by Thematic analysis.

This research has been approved by the research ethics board already.

III. RESULTS

\section{A. Access service}

General information. We found that $58.2 \%$ female, 56.7 \% ages of 41-50 years, $17.4 \%$ of admissions in the morning and $20.5 \%$ slightly injured (Non-Urgent) 64.1\% moderately severe (Urgent), and $15.4 \%$ more severe the injury (Emergency), the average time that trauma care at emergency room was 86.4 minutes. (standard deviation 42.6, range 10 to 210 minutes) (Table 1 ).

Patients travel to the hospital on their own found $43.3 \%, 35.1 \%$, Ambulance and rescue vehicle through 1669, and $7.4 \%$ refer from another hospital, $9 \%$ by private foundation, $5.1 \%$ rescuers car not through 1669. (Table 1).

Satisfaction of patient when using emergency rooms found that those who received $55.6 \%$ and $68.9 \%$ satisfied rescue vehicle contacted through 1669 more than another group. (Table 2)

Safety to use rescue vehicle. Patients travel to the hospital on rescue vehicle contacted through 1669 were safe. (Table 2).

TABLE I

GENERAL INFORMATION

\begin{tabular}{|l|c|c|}
\hline \multicolumn{1}{|c|}{ Data } & $\mathbf{N}$ & $\%$ \\
\hline 1. Service users & & \\
1.1 Patients & 163 & 41.8 \\
1.2 Relative & 227 & 58.2 \\
\hline 2. Sex & & \\
\hline 2.1 Male & 169 & 43.3 \\
\hline
\end{tabular}

\begin{tabular}{|c|c|c|}
\hline 2.2 Women & 221 & 56.7 \\
\hline \multicolumn{3}{|c|}{ 3. Age (year) $($ Mean \pm S.D) $=49.7 \pm 23.4(\min 3, \operatorname{Max} 98)$} \\
\hline 4. Time service (minute) & 210 & 53.8 \\
\hline \multicolumn{3}{|l|}{ 5. Level of Trauma } \\
\hline 5.1 Non-Urgent & 80 & 15.4 \\
\hline 5.2 Urgent & 250 & 64.1 \\
\hline 5.3 Emergency & 60 & 20.5 \\
\hline \multicolumn{3}{|c|}{$\begin{array}{l}\text { 6. Time in Emergency Room (minute) }(\text { Mean } \pm \text { S.D })= \\
86.41 \pm 42.6\end{array}$} \\
\hline \multicolumn{3}{|l|}{ 7. Getting to the hospital } \\
\hline $\begin{array}{l}\text { 7.1 By Ambulance and Rescue } \\
\text { vehicle through } 1669\end{array}$ & 137 & 35.1 \\
\hline $\begin{array}{l}\text { 7.2 By Ambulance and Rescue } \\
\text { vehicle not through } 1669\end{array}$ & 20 & 5.1 \\
\hline 7.3 By Private foundation & 35 & 9 \\
\hline 7.4 By Their own & 169 & 43.3 \\
\hline 7.5 By Refer from another hospital & 29 & 7.4 \\
\hline
\end{tabular}

TABLE II

PATIENTS TRAVEL TO EMERGENCY ROOM OF HOSPITAL IN REGIONAL HEALTH 3

\begin{tabular}{|l|c|c|c|c|}
\hline $\begin{array}{c}\text { Patients travel to } \\
\text { Emergency room } \\
\text { of hospital }\end{array}$ & $\mathbf{N}$ & $\begin{array}{c}\text { Satisfacti } \\
\text { on (\%) }\end{array}$ & $\begin{array}{c}\text { Safety } \\
(\%)\end{array}$ & $\begin{array}{c}\text { Want to } \\
\text { service } \\
(\%)\end{array}$ \\
\hline $\begin{array}{l}\text { 1. By Ambulance } \\
\text { and rescue vehicle } \\
\text { through 1669 }\end{array}$ & 137 & 55.6 & 96.4 & 94.9 \\
\hline $\begin{array}{l}\text { 2. By Ambulance } \\
\text { and rescue vehicle } \\
\text { not through 1669 }\end{array}$ & 20 & 50 & 85 & 75 \\
\hline $\begin{array}{l}\text { 3. By private } \\
\text { foundation }\end{array}$ & 35 & 68.9 & 94.3 & 91.4 \\
\hline
\end{tabular}

\section{B. Emergency Medical Services.}

Provision of trauma care in Emergency Medical Services System of Ministry of Public Health Hospitals in Regional3 were accredited standardization and mostly accredit by Hospital Accreditation standard. Trend of lacking staff and workforce in emergency room, Emergency Medicine Physicians, Nurse were still problem in the Ministry of Health hospitals. Trend of types trauma were increase with emergency cases. (Table 3) 
TABLE III

EMERGENCy Medical SERVICES System of Hospital in REgional Health 3

\begin{tabular}{|c|c|c|c|c|c|}
\hline Data & Tertiary Hospital & General Hospital 1 & General Hospital 2 & $\begin{array}{c}\text { Community } \\
\text { Hospital } 1\end{array}$ & $\begin{array}{l}\text { Community } \\
\text { Hospital } 2\end{array}$ \\
\hline $\begin{array}{l}\text { Service Information } \\
\text { - Size of bed }\end{array}$ & 653 & 405 & 365 & 90 & 30 \\
\hline $\begin{array}{l}\text { Staff in Emergency } \\
\text { room }\end{array}$ & $\begin{array}{lll}\text { EMT-B - } & \text { person } \\
\text { EMT-I } 7 & \text { person } \\
\text { EMT-P - } & \text { person }\end{array}$ & $\begin{array}{l}\text { EMT-B - } \\
\text { EMT-I } 2 \text { person } \\
\text { EMT-P - person }\end{array}$ & $\begin{array}{ll}\text { EMT-B - } & \text { person } \\
\text { EMT-I } 1 & \text { person } \\
\text { EMT-P - } & \text { person }\end{array}$ & $\begin{array}{ll}\text { EMT-B - } & \text { person } \\
\text { EMT-I - } & \text { person } \\
\text { EMT-P - } & \text { person }\end{array}$ & $\begin{array}{lll}\text { EMT-B } 1 & \text { person } \\
\text { EMT-I } 1 & \text { person } \\
\text { EMT-P - } & \text { person }\end{array}$ \\
\hline $\begin{array}{l}\text { Emergency Medicine } \\
\text { Physicians }\end{array}$ & 3 person & 1 person & - person & - person & - person \\
\hline Ambulance & 2 Cars & 4 Cars & 3 Cars & 2 Cars & 2 Cars \\
\hline Standardization & $\begin{array}{c}\text { Hospital } \\
\text { Accreditation(HA) }\end{array}$ & $\begin{array}{c}\text { Hospital } \\
\text { Accreditation(HA) }\end{array}$ & $\begin{array}{c}\text { Hospital } \\
\text { Accreditation(HA) }\end{array}$ & $\begin{array}{c}\text { Hospital } \\
\text { Accreditation(HA) }\end{array}$ & $\begin{array}{c}\text { Hospital } \\
\text { Accreditation(HA) }\end{array}$ \\
\hline Referral Center & $\sqrt{ }$ & $\sqrt{ }$ & $\sqrt{ }$ & $\sqrt{ }$ & $\sqrt{ }$ \\
\hline - Refer in province & $\sqrt{ }$ & $\sqrt{ }$ & $\sqrt{ }$ & $\sqrt{ }$ & $\sqrt{ }$ \\
\hline
\end{tabular}

EMT-B = Emergency Medical Technician Basic

EMT-I = Emergency Medical Technician Intermediate

EMT-P = Emergency Medical Technician Paramedic

\section{Problem affect service and access service}

\section{1) workload and administrative personnel.}

Problem was not enough manpower burden of responsibility in emergency medicine. Is still a problem in hospitals, the Ministry of Health in Region Health3 which cannot handle the problems of the area. For the problem of the FR(First responder) of emergency medical services with volunteers to do with the lack of assessment work continues. Evaluation or do not meet the criteria.

Problem for human resource development in a medical emergency.

\section{2) Service were unavailable in emergency medical room}

Problems of Service system in emergency medicine room, both of Hospital Care and pre- Hospital Care were problem of evaluation based on indicators such as Mortality Rate, Response time was also an issue that needs to be constantly evolving.

Problem of Referral system. The unavailability of the referral system so problems between provinces. The District Inspector No agreement clearly.

Problem with the financing. The issue is not just the budget that has been allocated to the f. Operating in a statement. Statements and development the hospital was the primary network. Requires the maintenance of the hospital. Or the budget of local authorities. Joined to develop a system to be effective, such as training seminars for the year.

Problem was unavailable in Ambulance and rescue vehicle and supplies and equipment and devices

\section{3) Hospital information systems.}

Information systems in hospital emergency also found for Communications through Call center 1669, made public expectations with rescuers to save him was all about health need. People expect too much as it was to get patients home from hospital. The communication system released rescuers. And to give the public insight It was not enough variety, and not lack of knowledge and communication to the public and easy life.

\section{IV.DISCUSSION}

\section{A. Trauma care for patient}

Patient of trauma came to find that most of them were female. Ranged in age between 41-50 years of service in the morning with Urgent and the average time to treat in the emergency room at 86.4 minutes, which was consistent with these findings [6]. Recommend that. development of appropriate should aim to achieve a balance of development services for trauma care and other patients.

The satisfaction of patient of trauma who received services. Once the service overall, found that them were very satisfied in accordance with the Research Institute of Emergency Medicine [9] the emergency medical service operations as possible. The second was satisfied with the services of the emergency room at a high level. And in line with Research [10] The satisfaction rating of the emergency medical services that serve the 
emergency room of the hospital, with an average satisfaction level.

\section{B. Service Provider}

Provision of trauma care in Ministry of Public Health Hospitals Regional Health 3 and trying to focus on patient-centered with trauma care by certified of Hospital accreditation every hospital. They were also developing services. To meet the conditions of public emergency such as Fast track STEMI, Fast track Stroke. Compare rates were found dead in the emergency room, the mortality rates in emergency rooms increased, possibly due a main road between the provinces as accidents were more likely. Therefore, the number of injuries was increasing. Inadequacy of staff of emergency room may affect to help patients survivors [6]. The research found that access to service delivery was still very limited [6] found that service delivery in USA and doctors had been a role in the leadership and supervision system. This was to ensure that treatment. According purposed establishment of pre-hospital care operations.

Staff in emergency room of the hospital It also found that shortages in many fields, including emergency medicine, nurse, EMT. Emergency Medicine Physicians available in Region Health3 were lower than the minimum of country 3 staff were assigned to the hospital [11] The minimum criteria set 2-3 / District, also found that the lack of compliance with the fullness [6], continuing the trend of manpower in emergency medicine were the factors that made the decision to move to work in the private hospital, including improper compensation. Emergency Medicine physician who practices an average of 300 hours / month. Than workers in regular time (176 hours), which mainly operate in urban areas.

Human resource development for staff in the emergency room of the hospital and FR to join in a medical emergency, such as local authorities., Foundations and the private sector are the highlights of the Health Network of Region 3 that have been implemented in a systematic manner, held OD (Organization Development) and Rally. A lecturer in the field of resuscitation service plan development community hospital. Forms part of the network [7]
Information technology in hospitals the Ministry of Health Region 3 in the area of health communication to the public in 1669 were satisfied with the service call. Despite the restrictions on service-oriented systems that could cause the public to understand. 1669 that can be provided all health matters. Including application development central computer or Application that facilitates communication and coordination between the service providers in the system and save the data to be used in the management plan in the year ahead, including comparable indicators between hospitals. [9], [7]. Coupled with direct experience (Tacit knowledge) and knowledge in other ways (such as clinical practice guideline, care map) regularly. To enhance learning and improve performance. Step up to a change in both the quantity and quality of jobs and the development of information technology was appropriate. Focus on working with the proxy and performance data to be used for patient care, and community. Design and develop in this direction. I want to be involved or even the introduction of the prototype units is critical. This should take into account the exchange of data between services and network services. The conditions for transmission to patients without seams (Seamless Health Care).

\section{LIMITATIONS}

Application for certification Ethical Research Be conducted by certified of hospital can keep almost all hospitals. Delays in obtaining certification. Since research was storage area network services. As it must be in the hospital several levels. The relevant authorities should consider This point for the purpose of research and effectiveness

\section{WHAT SHOULD BE MORE STUDY}

1. Should research Pre-Hospital Care in order to bring the findings to plan prevention for accidents in the future.

2. Participation of FR (First Responder) as well as rescue and resuscitation. The medical system in emergency. Local governments and foundations And private organizations.

\section{RECOMMEND FOR POLICY}

1. Emergency medical policy at the national level with the Ministry of Health and the Institute of 
Medical Emergency. Directed and policy Public authorities should understand the practitioners to clear. The performance will be in the direction and guidance throughout the country.

2. The Ministry of Health and the Institute of Medical Emergency should strategic plan to10 years for the production of medical emergency. And emergency medical personnel In accordance with the Service Plan and allocate manpower of the health cover hospital every level, and should be produced and distributed workforce using demand-based approach which takes into account the purchasing power. Education level and the burden on service

3. Administrator of medical emergency should give priority to emergency medical system and in the Pre-Hospital Care and Hospital Care collaboratively with all stakeholders, especially the Ministry of the Interior and Local Government. To the development of the emergency medical system to have flexibility and efficiency.

4. Medical staff in emergency management system, should be encouraged to further develop their knowledge and skills trainers. A knowledge sharing between hospitals with emergency physicians and hospitals that have no doctor, both within the province and within the region.

5. Promote and support local governments took part and a function or role in the operation. Since the strategic planning process with the provincial emergency. And hospitals in areas such as budgeting, planning, training in the province, rescuers car, truck and machine stretch.

\section{REFERENCES}

[1] World Health Organization.(2013). World Health Statistics 2013 [Search on December 30,2014]; Available from URL: http://www.who.int/gho/publications/world health_statistics/2013

[2] The Office of Inspector General, Ministry of Health, district health services 3. Strategic plan Area Health Service 3, 2557 to 2559. Nakhon Sawan. 2014.

[3] World Health Organization. Monitoring the building blocks of health systems: A handbook of indicators and their measurement strategies. Geneva. 2010

[4] National Institute of Emergency Medicine. (2014). Annual Report 2556. The National Institute of Emergency Medicine. [searched on December 30, 2014]; Available from URL: http://www.niems.go.th/th/ View / Data Service.

[5] Paiboon Suriyawongpaisarn. (2009). A series of research projects to the evaluation and development of emergency medical services. Health Insurance System Research Office of Thailand Affiliated Health
Systems Research Institute. [searched on October 20,2010]; Available from:URL: http://www.hisro.or.th/main/modules/research.

[6] Tanongsan Tantavorn. (2013). Report reviewed the development of emergency medical services in Thailand under the project. "A review of international experience In the development of emergency medical services. Health Insurance System Research Office of Thailand. Network Health Systems Research Institute. [searched on December 10, 2013]; Available from: URL: http: //www.hisro. .or.th / main / modules / research.

[7] Paiboon Suriyawongpaisarn. (2015). The project is estimated to serve patients admitted to hospital for 3 funds under the policy to all emergency treatment. Cover everyone. Office of Research and Development Health Thailand Network Health Systems Research Institute. [searched on January 10, 2015]; Available from: URL: http: /. /www.hisro.or.th/main/modules/research.

[8] Samrit Srithamrongawat.(2014).The review of international experience in the development of emergency medical services and lessons for Thailand. Health Insurance System Research Office of Thailand. (GIT cover) Network Health Systems Research Institute (bright flavor.) [Serial online]. [searched on December 10, 2014]; Available from: URL: http: //www.hisro. .or.th / main / modules / research.

[9] National Institute of Emergency Medicine. (2011). The satisfaction of the public to provide emergency medical services for the year 2554. [Searched on January 5, 2015]; Available from: URL http://www.niems.go.th/th/View. / Data Service

[10] WannaRa Chenwattana.(2012). The satisfaction rating of the emergency medical services (EMS) Assessment of Client's Satisfaction towards for Emergency Medical Service (EMS). [Searched on April 9, 2015]; Available from.:URL: http://www.niems.go.th/th/.

[11] Nonglak Pakaya. The trend of manpower in emergency medicine. Conference on Emergency Medicine 2556 annual national "associate medical emergency Thailand. Towards Asia, "March 8, 2013.

[12] Bureau of Non-Communicable Diseases Department of Disease Control, Ministry of Health.(2014).Road accident statistics, the county health service year 2554-2556. (Retrieved on January 10, 2015) Available from: URL: http://thaincd.com/information.statistic/injuried data /.

[13] Creswell JW, Plano Clark VL. Designing and conducting mixed methods Research. Thousand Oaks, CA: Sage Publication. York: McGraw-Hill;2007. 